\title{
Uncommon Complication for Commonly Used Drugs: Cardiac Arrest after Administration of Succinylcholine
}

\author{
Mohd Nazri A, Nor Hidayah ZA*, Suryati MP, Wan Nasrudin WI, Azhar M, Mazelan O, \\ Nurul Ashikin H, Fazilawati Z, Maziah M, Khairul Has H and Puzizer S
}

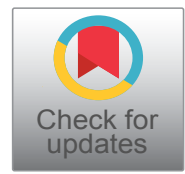

Anaesthesia and Intensive Care Department, Hospital Raja Perempuan Zainab II, Malaysia

*Corresponding author: Nor Hidayah Zainool Abidin, Anaesthesia and Intensive Care Department, Hospital Raja Perempuan Zainab II, Kota Bharu, Kelantan, Malaysia, E-mail: nhza85@yahoo.com

\begin{abstract}
Succinylcholine is a depolarizing, muscle relaxant, that commonly used to facilitate endotracheal intubation, especially in emergency surgery or patient with difficult intubation. However succinylcholine is associated with severe hyperkalaemia, arrhythmia and cardiac arrest especially in severe burn and neuromuscular disease and renal failure. We report a case of young boy with underlying Obstructive Sleep Apnoea (OSA) presented for bleeding post tonsillectomy, who developed cardiac arrest following administration of succinylcholine. In this case report, we discuss regarding possible mechanism and treatment.
\end{abstract}

\section{Keywords}

Succinylcholine, Cardiac arrest, Rhabdomyolysis, Ventricular fibrillation

\section{Introduction}

Succinylcholine is an old depolarizing muscle relaxant, commonly used to facilitate endotracheal intubation especially in emergency surgery. It is a very popular muscle relaxant in view of the favorable pharmacokinetic property that are predictable fast onset and short duration of action. Few of the known side effect of succinylcholine are hyperkalaemia, cardiac arrhythmia and cardiac arrest [1]. Even though this is a very rare complications, it is fatal and can cause high morbidity and mortality if hyperkalaemia is not managed accordingly [2].

\section{Case Presentation}

We report a case of 12-years-old boy with underlying OSA, who was on home CPAP machine. He was obese with body mass index of $35 \mathrm{~kg} / \mathrm{m}^{2}$. He was diagnosed to have recurrent tonsillitis and was schedule for elective Adenotonsillectomy. Premedication round was done prior to surgery and no obvious abnormality detected. No premedication drug was given on the night prior to surgery. Baseline blood investigations were normal; white blood cell count of $10.6 \times 10^{\wedge} 9 / \mathrm{L}$, hemoglobin was $13.6 \mathrm{~g} / \mathrm{dL}$, hematocrits of $42 \%$ and platelet count was $385 \times 10^{\wedge} \mathrm{g} / \mathrm{L}$; renal profile: Blood urea of $3.9 \mathrm{mmol} / \mathrm{L}$, sodium of $137 \mathrm{mmol} / \mathrm{L}$, potassium of 4.3 $\mathrm{mmol} / \mathrm{L}$. No arterial blood gas (ABG) available prior to surgery.

Hemodynamic was stable prior to induction in operation theatre (OT) with blood pressure (BP) of 121/82 $\mathrm{mmHg}$ and pulse rate (PR) of 108 beats/min and no arrhythmia on cardiac monitor, oxygen saturation was $100 \%$ under room air. He was induced using total intravenous anaesthesia (TIVA) using intravenous (IV) Propofol and Remifentanil. IV Atracurium $40 \mathrm{mg}(0.5$ $\mathrm{mg} / \mathrm{kg}$ ) was given to facilitate intubation. Intubation and ventilation was uneventful. Hemodynamic was stable throughout the surgery. Blood lost was minimal and patient was extubated post-operatively. He was observed in the recovery bay for 30 minutes where blood pressure and heart rate was stable before admitted to Intensive care unit (ICU) for monitoring in view of patient was on home CPAP machine prior to surgery.

However, when the patient arrived in ICU, he had few episodes of vomiting mixed with blood about 200 $\mathrm{ml}$. BP was low, $88 / 55 \mathrm{mmHg}$ and heart rate was 140

Citation: Mohd NA, Nor Hidayah ZA, Suryati MP, Wan Nasrudin WI, Azhar M, et al. (2018) Uncommon Complication for Commonly Used Drugs: Cardiac Arrest after Administration of Succinylcholine. Int J Anesthetic Anesthesiol 5:071. doi.org/10.23937/2377-4630/1410071

Accepted: August 02, 2018: Published: August 04, 2018

Copyright: (C) 2018 Mohd NA, et al. This is an open-access article distributed under the terms of the Creative Commons Attribution License, which permits unrestricted use, distribution, and reproduction in any medium, provided the original author and source are credited. 


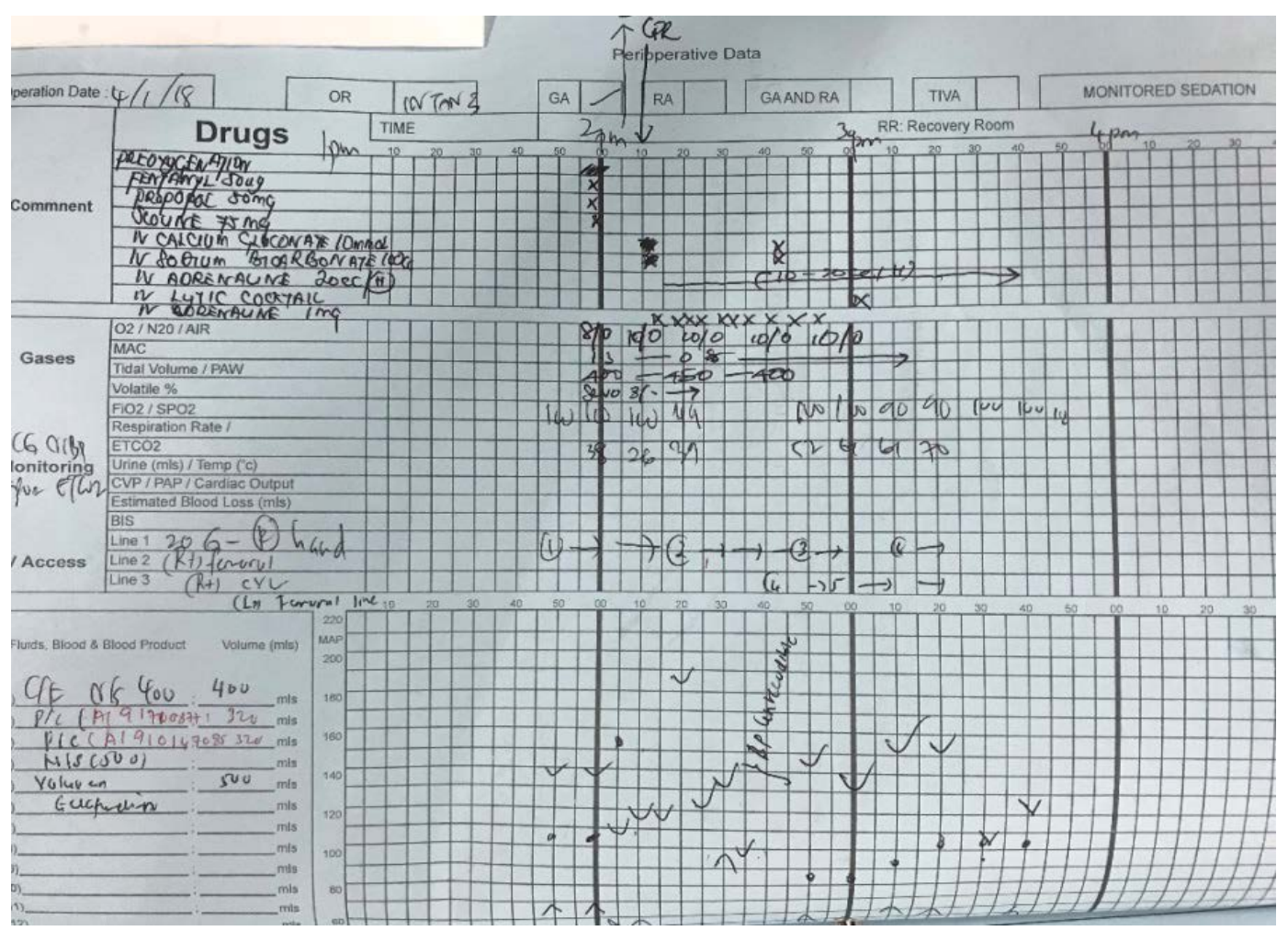

Figure 1: Patient's General Anaesthesia form during the incidence.

beats/min. He was given intravenous normal saline $0.9 \%$ about $10 \mathrm{cc} / \mathrm{kg}$ then blood pressure was subsequently normal. The Ear, Nose and Throat (ENT) surgeon was informed to review the patient urgently and he was subsequently decided for wound exploration in OT for bleeding post-tonsillectomy. He was transferred to OT for urgent surgery. The patient remains conscious and alert, BP was $130 / 70 \mathrm{mmHg}$ and pulse rate was 110 beats/min and oxygen saturation $\left(\mathrm{SpO}_{2}\right)$ was $99 \%$ under nasal prongs $3 \mathrm{~L} / \mathrm{min}$. He was induced with IV fentanyl $50 \mathrm{mcg}$, IV propofol $50 \mathrm{mg}$ and IV succinylcholine $75 \mathrm{mg}$. Intubation was uneventful. Initial vital signs post intubation was BP of $130 / 70 \mathrm{mmHg}$, pulse rate of 105 beats/ min and $\mathrm{SpO}_{2}$ was $100 \%$ and end tidal $\mathrm{CO}_{2}\left(\mathrm{ETCO}_{2}\right)$ was $37 \mathrm{mmHg}$ Figure 1.

It was unexpected that five minutes after intubation, noted brief episodes of ventricular fibrillation (VF) on cardiac monitor followed by asystole. Cardiopulmonary resuscitation (CPR) was commenced, and then patient developed VT and VF. Biphasic defibrillation with 100 joules, then twice with 150 joules before sinus rhythm was restored. Total duration of CPR before return of spontaneous circulation (ROCS) was 20 minutes. During $\mathrm{CPR}$, total of $7 \mathrm{mg}$ IV adrenaline was given to patient. After ROCS, blood pressure was $70 / 45 \mathrm{mmHg}$, heart rate $130 \mathrm{bpm}, \mathrm{IV}$ noradrenaline at $0.3 \mathrm{mcg} / \mathrm{kg} / \mathrm{min}$ and IV Adrenaline at $0.2 \mathrm{mcg} / \mathrm{kg} / \mathrm{min}$ was started to support the BP. BP pickup to $112 / 65 \mathrm{mmHg}$ and heart rate was 140 beats/min. Arterial blood gaseous (ABG) was done post resuscitation and showed severe metabolic acidosis with hyperkalemia; The $\mathrm{pH}$ was $6.83, \mathrm{pCO}_{2}$ was 45.3 $\mathrm{mmHg}$, pO , was $250 \mathrm{mmHg}$, Bicarbonate was $7.3 \mathrm{mmHg}$ and base excess of negative $26.4 \mathrm{mmHg}$ and potassium was $6.4 \mathrm{mmol} / \mathrm{L}$. Immediate action were taken, we started sodium bicarbonate $\left(\mathrm{NaHCO}_{3}\right)$ 8.4\%, $100 \mathrm{mls}$ slow bolus over 20 minutes, IV calcium gluconate $10 \mathrm{mmol}$, IV insulin 10 unit and IV dextrose $50 \%, 50$ mls. Repeat ABG after 1 hour show some improvement with the $\mathrm{pH}$ of 7.18, $\mathrm{pCO}_{2}$ of $48 \mathrm{mmHg}, \mathrm{pO}_{2}$ of $235 \mathrm{mmHg}$, bicarbonate of $17 \mathrm{mmol}$ and base excess of $-16 \mathrm{mmol}$. Surgery was continued since patient was stable following resuscitation. Noted large amount of blood clot at left superior pole of tonsillar bed with slow oozing after blood clot removed. The bleeding was able to be secured.

Patient was transferred back to ICU for post resuscitation care. In ICU, hemodynamics was supported with IV Noradrenaline and IV Adrenaline. An electrocardiogram postoperatively showed sinus tachycardia. A transthoracic echocardiography showed no abnormality at all. The patient regained full consciousness after 12 hours post event despite still on double vasopressors. He developed rhabdomyolysis with creatine kinase (CK) of $7200 \mathrm{U} / \mathrm{L}$ and also anuric acute kidney injury (AKI), which required intermittent dialysis. Vasopressors support was off after 48 hours and he was extubated after 72 hours in ICU. Patient general condition was improved and stayed in ICU for total of nine days and dialysis was done at every other day (EOD) during ICU stay. Patient was discharged to general ward and stayed for another 10 days. He was dialyzed twice in general ward before discharged home. Upon discharged, patient was well and urine output was good with improving renal function. Renal profile before discharged was markedly improved and he was under nephrologist follow-up 
upon discharged from hospital. He was able to go back to school after one week resting at home. Patient cognitive and memory was good on subsequent follow-up and there was no memory regarding the event.

\section{Discussion}

Succinylcholine is depolarizing muscle relaxant drug, commonly used worldwide, as a drug of choice to facilitate rapid sequence intubation (RSI) especially in emergency surgery or patient with difficult airway [3]. Acetylcholine and succinylcholine both activate the acetylcholine (Ach) receptor at the motor end plate of striated muscles, subsequently will lead to depolarization of the muscle membrane and subsequently efflux of potassium ion. Succinylcholine produces a longer depolarization of muscle membrane compared with acetylcholine [2]. This is accompanied by fast leakage of potassium into the circulation leading to increase of serum potassium concentration of 0.2 to $1 \mathrm{mmol} / \mathrm{L}$ in healthy person. RSI with IV succinylcholine and propofol was done in this patient in view of to anticipate difficult intubation as this patient is obese with OSA and also having active airway bleeding. Despite the gold standard for RSI, succinylcholine serious adverse effects soon become evidence in multiple reported cases [4-6].

In compromised patient, for example in burns, uremia, disused atrophy and myopathy, a sudden severe hyperkalaemia may result in cardiac arrest [1]. Howev$\mathrm{er}$, in this patient, baseline potassium was $4.3 \mathrm{mmol} / \mathrm{L}$. By increasing 0.5 to $1 \mathrm{mmol} / \mathrm{L}$, patient's plasma level of potassium may raise higher than $5.3 \mathrm{mmol} / \mathrm{L}$. This level is more than enough to trigger arrhythmia especially in the patient with hemodynamic instability such as bleeding post adenotonsillectomy with compromised airway, so with the element of tissue hypoxia may cause cardiac muscle become irritable and easily developed cardiac arrhythmia. The issue of whether to use succinylcholine or rocuronium for rapid sequence induction has been continuously debated $[7,8]$. However since our patient was stable prior to induction and sugammadex was not widely available, succinylcholine was still is the drug of choice in this patient.

This patient also had significant amount of blood loss before proceed with second surgery, will lead to hypotensive and tachycardia of which was well resuscitated. Significant bleeding also can lead to rhabdomyolysis, cause destruction of cell wall and will cause release of intracellular contents like Potassium, magnesium, phosphate [2]. It will contribute to hyperkalemia in this patient and subsequently cardiac arrhythmia. Patient also developed cardiac arrest and required CPR. CPR itself can worsen rhabdomyolysis [9]. Furthermore, retrospective interview of this patient noted no history of sudden cardiac death, musculoskeletal disease or myopathy to support this illness. There was a reported case of cardiac arrest in the patient post-adenotonsil- lectomy due to unrecognized rhabdomyolysis where most probably the patient had heritable metabolic myopathies but demonstrate negative test for $\mathrm{MH}$ [5]. Bleeding also will lead to metabolic acidosis especially if volume of blood loss was not replaced accordingly in this patient which may exacerbate the hyperkalaemia. This is supported by one reported case in patient with severe metabolic acidosis and haemorrhage [10].

\section{Conclusion}

At present very limited option available for short acting non-depolarizing relaxant for RSI like succinylcholine except high dose rocuronium [11]. However, if succinylcholine is indicated, it must be used with caution due its side effect especially related to cardiac arrhythmias [12]. This case is hopefully giving a lesson that any young child presented with haemorrhage required careful consideration of the use of succinylcholine and when they develop arrhythmias, hyperkalaemia should be suspected and managed rapidly to prevent resistant arrhythmias during surgery. Even though this case is rare, none the less asystole and death is devastating to the relatives and medical personnel.

\section{References}

1. Martyn JA, Richtsfeld M (2006) Succinylcholine-induced hyperkalemia in acquired pathologic states: Etiologic factors and molecular mechanisms. Anesthesiology 104: 158169.

2. Gronert GA (2001) Cardiac arrest after succinylcholine: Mortality greater with rhabdomyolysis than receptor upregulation. Anesthesiology 94: 523-529.

3. Frerk C, Mitchell VS, McNarry AF, Mendonca C, Bhagrath $R$, et al. (2015) Difficult airway society 2015 guidelines for management of unanticipated difficult intubation in adults. $\mathrm{Br} \mathrm{J}$ Anaesth 115: 827-848.

4. Cecchini J, Colchen-Personne A, Mellot F, Fischler M (2014) Cardiac arrest and succinylcholine-induced hyperkalemia in a patient with a triton tumor. A A Case Rep 3: 76-77.

5. Lee G, Antognini JF, Gronert GA (1994) Complete recovery after prolonged resuscitation and cardiopulmonary bypass for hyperkalemic cardiac arrest. Anesthesia \& Analgesia 79: $172-174$

6. Wood B, Ismail K (2016) A cardiac arrest following the administration of succinylcholine. Acta Anaesthesiol Belg 67: 97-99.

7. Joseph PJ, Jacques L, George W (2002) Are intubation conditions using rocuronium equivalent to those using succinylcholine? Acad Emerg Med 9: 813-823.

8. Tran DTT, Newton EK, Mount VAH, Lee JS, Mansour C, et al. (2017) Rocuronium vs. succinylcholine for rapid sequence intubation: A cochrane systematic review. Anaesthesia 72: 765-777.

9. Minor RL Jr, Chandran PK, Williams CL (1990) Rhabdomyolysis and myoglobinuric renal failure following cardioversion and CPR for acute MI. Chest 97: 485-486.

10. Schwartz DE, Kelly B, Caldwell JE, Carlisle AS, Cohen, NH (1992) Succinylcholine-induced hyperkalemic arrest in a patient with severe metabolic acidosis and exsanguinating hemorrhage. Anesthesia \& Analgesia 75: 291-293. 
11. Kumar RR, Kumari R, Kumar A (2016) Rocuronium versus succinylcholine: A clinical comparison of two muscle relaxants for rapid sequence induction of anaesthesia. International Journal of Advances in Medicine 3: 596-601.
12. Kovarik WD, Morray JP (1995) Hyperkalemic cardiac arrest after succinylcholine administration in a child with purpura fulminans. Anesthesiology 83: 211-213. 